\title{
An Epidemiological Study of Cardiovascular Risk Factors in Patients with Myocardial Infarction: A Prospective Study
}

\author{
Hosseinali Jelveh Moghaddam, ${ }^{1}$ Azar Avazeh, ${ }^{2}$ Shahram Saifi, ${ }^{3}$ Masoum Khoshfetrat, ${ }^{4}$ Alireza \\ Sedaghat, ${ }^{5}$ Reza Shahrami, ${ }^{6}$ Sevak Hatamian, ${ }^{7}$ Ali Amirsavadkouhi, ${ }^{8}$ Mehdi Ghahremani, ${ }^{9}$ Seyed \\ Mohammadmasoud Moosavinasab, ${ }^{9}$ Mohammadali Khabirikhatiri, ${ }^{10}$ Hosna Forooghirad, ${ }^{11}$ Farzaneh
}

Baghernezhad, ${ }^{12,13}$ Leila Safaeepoor, ${ }^{13,14}$ and Farshid Rahimibashar ${ }^{15,{ }^{*}}$

${ }^{1}$ Department of Anesthesia, Shahid Modarres Hospital, Shahid Beheshti University of Medical Sciences, Tehran, IR Iran

${ }^{2}$ Faculty of Nursing and Midwifery, Zanjan University of Medical Sciences, Zanjan, IR Iran

${ }^{3}$ Anesthesia and Critical Care Medicine Department, Rohani Hospital, Babol University of Medical Sciences, Babol, IR Iran

${ }^{4}$ Anesthesia and Critical Care Medicine Department, Khatamolanbia Hospital, Zahedan University of Medical Sciences, Zahedan, IR Iran

${ }^{5}$ Anesthesia and Critical Care Medicine Department, Imam Reza Hospital, Mashhad University of Medical Sciences, Mashhad, IR Iran

${ }^{6}$ Kowsar Hospital, Alborz University of Medical Sciences, Karaj, IR Iran

${ }^{7}$ Anesthesia and Critical Care Medicine Department, Shahid Madani Hospital, Alborz University of Medical Sciences, Karaj, IR Iran

${ }^{8}$ Anesthesia and Critical Care Medicine Department, Mehrad Hospital, Tehran, IR Iran

${ }^{9}$ Anesthesia and Critical Care Medicine Department, Shahid Modares Hospital, Shahid Beheshti University of Medical Sciences, Tehran, IR Iran

${ }^{10}$ Anesthesiology Research Center, Taleghani Hospital, Shahid Beheshti University of Medical Sciences, Tehran, IR Iran

${ }^{11}$ Biology Department, Basic Sciences Faculty, Payame Noor University, Tehran, IR Iran

${ }^{12}$ Trauma Research Center, Baqiyatallah University of Medical Sciences, Tehran, IR Iran

${ }^{13}$ Nursing Faculty, Baqiyatallah University of Medical Sciences, Tehran, IR Iran

${ }^{14}$ Behavioral Sciences Research Center, Baqiyatallah University of Medical Sciences, Tehran, IR Iran

${ }^{15}$ Department of Anesthesiology, School of Medicine Hamadan University of Medical Sciences, Hamadan, IR Iran

"Corresponding author: Farshid Rahimibashar, Department of Anesthesiology, School of Medicine Hamadan University of Medical Sciences, Hamadan, IR Iran. Tel: +98-8132640031, Fax: +98-8132651515, E-mail: fr_rahimibashar@yahoo.com

Received 2015 September 30; Accepted 2015 November 14.

\begin{abstract}
Background: Stress is one of the most important factors that may be accompanied with increased possible prevalence of cardiovascular diseases including myocardial infarction.

Objectives: The purpose of this study was to investigate the correlation between perceived stress intensity and some cardiovascular risk factors in myocardial infarctions' patients.

Methods: The design of the study was cross sectional. Overall, 2400 patients with myocardial infarction were chosen through multistage random sampling. A three-part questionnaire including demographic characteristics, perceived stress, and a checklist to record laboratorial test and electrocardiography changes were used for data collection.

Results: The results of the present study showed that $45 \%$ of the patients had moderate and $55 \%$ had severe stress. Moreover, findings of the research indicated that there were significant differences between the mean stress level in various categories of the variable including gender, education, history of hypertension, blood pressure, diabetes, cigarette smoking, exercising, job, and family history of myocardial diseases.

Conclusions: Regarding the high level of perceived stress in patients with myocardial infarction, it is necessary to devise a program and determine stressor factors to modify and decrease them.
\end{abstract}

Keywords: Cardiovascular Diseases, Cardiovascular Diseases Risk Factors, Perceived Stress, Myocardial Infarction

\section{Background}

Today, cardiovascular diseases are considered as the most common and serious diseases in developing countries (1-6). In 2013, the rate of prevalence of cardiovascular diseases was about 71.3 million (34.2\%) in the United States (7). Coroner vessel diseases had the first rank and these kinds of diseases were the most common causes of death in both developed and developing countries $(8,9)$. American researchers of the Heart Association showed that about 13.2 million patients ( $6.9 \%$ of the whole American population) had heart coroner vessel diseases in 2013. The rate of death was about 479300 people, where $53 \%$ of the total deaths had occurred in the United States (7). Researchers also 
showed that the rate of survival after confinement was very low (10). The World Health Organization's report approved that the rate of cardiovascular diseases is increasing, with these diseases being the underlying cause of $48.6 \%$ of all deaths, and the rate is expected to rise to $46.4 \%$ by 2020 (1113).

In Iran, like most countries, the main cause of death is cardiovascular diseases $(5,14)$ and causing $35 \%$ of deaths in Iran. The number of deaths due to cardiovascular diseases has been reported as 15326 cases (36.35\%) in Tehran for the year 2010 (5).

There are many risk factors associated with cardiovascular diseases. Recent advancements for the control of risk factors associated with cardiovascular diseases can help us deal with this health hazard (15-17). Many researches have focused on the context of cardiovascular diseases. Some studies are based on the treatment of these diseases and others are trying to determine the risk factors. Framingham's study showed that $50 \%$ of cardiovascular diseases depend on nine main risk factors. Risk factors include: age, gender, family history of cardiovascular diseases, the rate of blood cholesterol, the rate of high density lipoprotein of blood, hypertension, smoking, diabetes mellitus, and left ventricular hypertrophy $(5,18-20)$.

Effective factors in cardiovascular diseases are divided to three main types including: unchangeable factors (age, gender, preterm menopause and family history), changeable factors (smoking cigarettes, fatness, hypertension, diabetes mellitus, insufficient physical activities, increase of blood cholesterol, low lipoprotein and high lipoprotein of blood), and unapproved risk factors (insufficient use of vitamin B-complex, and hyper insulinemia) (21). Psychological factors are the other group of risk factors. They include depression, anxiety disorders, anger problems, roughness, and chronic stresses during life (22-24).

Stress may be accompanied with increase in the possibility of cardiovascular diseases. Some researches illustrated that stress is an important risk factor in cardiovascular diseases (25). In addition, stressful situations could effect peoples' health and also cause diseases such as coroner vessel disorders and hypertension (6).

Stress activates biological responses and also activates neural system, glands and the immune system. One of the main effects of biological stress response is sympathetic system activation and release of epinephrine. The most important systems that are affected by release of epinephrine are the cardiovascular systems. Sequential increase of heart rate and hypertension are expected with stress (26).

Studies have shown that the activation of the sympathetic system leads to the release of epinephrine by different stress factors, and subsequently, an increase in heart rate $(27,28)$. In this condition both blood pressure and pulse rate are increased (29-32) but the volume of lungs is decreased. Finally this marker can cause incidence of myocardial ischemia (33). Therefore, biologic response to stress can increase the possibility of cardiovascular diseases.

\section{Objectives}

However, this study attempted to show the relationship between rate of perceived stress and other main risk factors of heart coroner vessels diseases in patients with myocardial infarction.

\section{Methods}

This research was a cross sectional study, conducted from May 2011 to October 2013 on 2400 patients with myocardial infarction. The patients were hospitalized at coronary and post coronary heart units of ten affiliated hospitals to Tehran University of Medical Sciences (TUMS) during the process of research accomplishment. Sampling was done by multistage random sampling. Sampling in the first step was cluster random sampling. All educational and non-educational hospitals affiliated to TUMS were considered. From the 45 affiliated hospitals, ten hospitals were selected. In the second step, all coronary and post coronary heart units were considered as a cluster, and at each hospital, one unit through cluster random sampling was selected. In the third step, simple random sampling through computerized random sampling was done. The sample size was calculated through a pilot study $(\alpha=0.05$ and $\beta=$ 0.80). Ten percent attrition was considered for preventing of sampling bias. Inclusion criteria were patient's awareness, approval of myocardial infarction by clinical symptoms, serum enzyme tests, and heart tape pathological changes. For data collection, a three-part questionnaire including demographic characteristics (including age, gender, marital status, education, weight and height), perceived stress, and a checklist to record laboratorial test and Electrocardiography(ECG) changes were used. The validity of the three parts of the questionnaire was confirmed by a panel of experts, including three cardiologists, one interventionist, ten head nurses, and twenty nurses working at the coronary and post coronary units. The perceived stress questionnaire was designed by Kohn and Kamark (34). The Perceived Stress Scale (PSS) is the most widely used psychological instrument for measuring the perception of stress, which is a measure of the degree to which situations in one's life are appraised as stressful. Items were designed to 
determine how unpredictable, uncontrollable, and overloaded, respondents found their lives. The scale also included a number of direct queries about current levels of experienced stress. The PSS was designed for use in community samples with at least junior high school education. The items were easy to understand, and the response alternatives were simple to grasp. Moreover, the questions were of a general nature and hence were relatively free of content specific to any subpopulation group. The questions of the PSS ask about feelings and thoughts during the last month. In each case, respondents are asked how often they felt a certain way. The first version of this instrument had four questions, the second version had ten questions, and the third one had 14 questions. In this research, the third version, i.e. the 14-question instrument, was utilized. This instrument was designed, based on a Likert criteria including five choices (from never or none=1, to very much $=5$ ), and has been utilized in many researches; which was accomplished by examining a number of female teachers. Internal consistency (Cronbach's alpha) of the aforesaid study was 0.89 (35). The reliability of the research was examined through internal consistency (Cronbach's alpha) and was equal to 0.89 , which was acceptable. Questions number 4,5,6,7,9,10 and 13 are scored reversely (never or none $=5$, and very much $=1$ ). The least score that could be gained for perceived stress was 14 , and the most 70. The ethical considerations were related to the participants' autonomy, confidentiality and anonymity during the study period and study's publication. The participants were informed of the aim, the design of the study, and the voluntary nature of their participation. After data collection, all data were entered in the Statistical Package for Social Sciences (SPSS) software and analyzed by descriptive and inferential statistics, the data included gender, education level, hypertension, history of hypertension, diabetes, cigarette smoking, doing exercise, job, and family history of myocardial infarction.

\section{Results}

Overall, 2400 patients participated in this research; $6.5 \%$ of the patients were under 40 years of age, $15 \%$ between $41-50$ years, $33 \%$ between $51-60$ years, and $45.5 \%$ more than 60 years. Furthermore, $43.5 \%$ of the patients were female, and $56.5 \%$ were male; $81 \%$ were married, and the spouses of $19 \%$ had died. Regarding education, $45.5 \%$ of the patients were illiterate, $31.5 \%$ had elementary education, $17.5 \%$ high school education, and 5.5\% had university education. $10.5 \%$ of the patients had less than normal Body Mass Index (BMI) (19.9), 50.5\% had normal BMI and 39\% had BMI more than normal. $65 \%$ of the patients had normal blood pressures, and 35\% of them had hypertension.
$2.6 \%$ of the patients had previously history of hypertension; while $97.4 \%$ of the patients did not have previously history of hypertension. Eighty-four percent of the patients had normal serum level cholesterol, $16 \%$ had serum level cholesterol more than normal. Eighty percent had normal serum level triglyceride and $20 \%$ of the patients had more than normal serum level triglyceride. Regarding diabetes, $15.5 \%$ of the patients were affected by diabetes and $84.5 \%$ were not affected by diabetes. Sixty-six percent had no history of cigarette smoking and, 23\% had previous history of cigarette smoking and had given up before the research, and finally $11 \%$ were current smokers during the research. Four percent of the patients were exercising regularly, 30\% were exercising irregularly and 66\% were not exercising at all. Regarding job status, $10.5 \%$ were employees, $11.5 \%$ were workers, $38 \%$ were housekeepers, $2 \%$ were jobless, $11.5 \%$ were retired, and $26.3 \%$ had nongovernmental jobs. Furthermore, $88.5 \%$ of the patients were living in cities, and $11.5 \%$ were living in villages. Regarding history of cardiovascular diseases, $25.5 \%$ of the patients had a history of these diseases while $74.5 \%$ did not have so. Finally, $82.6 \%$ of the patients had no previous history of the use of contraceptive tablets and $17.4 \%$ had a previous history of utilizing contraceptive tablets. The mean and standard deviation of age, BMI, serum level of cholesterol, and serum level of triglyceride of the patients were $59.18 \pm 11.06,24.87$ $\pm 3.74,154.62 \pm 88$ and $206.70 \pm 56.39$, respectively.

The results of the research showed that more than half of the patients had severe stress (55\%) (Table 1). Statistical analysis showed that there was no significant differences between perceived stress categories and age $(\mathrm{F}=0.780$ and $\mathrm{P}=0.506)$, marital status $(\mathrm{F}=1.690$ and $\mathrm{P}=0.092)$, $\mathrm{BMI}(\mathrm{F}$ $=0.981$ and $\mathrm{P}=0.37)$, blood cholesterol level $(\mathrm{T}=0.691$ and $\mathrm{P}=0.451)$, blood triglyceride level $(\mathrm{F}=0.912$ and $\mathrm{P}=0.891)$, contraceptive tablets $(\mathrm{T}=0.641$ and $\mathrm{P}=0.356)$, and family relationship $(\mathrm{F}=0.394$ and $\mathrm{P}=0.811)$.

Relative and absolute frequencies, and statistical analyses of gender, education level, hypertension, history of hypertension, diabetes, cigarette smoking, doing exercise, job, and family history of myocardial infarction to compare with perceived stress categories are presented in Table 2.

\section{Discussion}

All subjects were affected with myocardial infarction; there was no one with low stress (score less than 23). This matter demonstrates that patients with myocardial infarction had more stress. This may be because of the increase of life stressors in various dimensions of life, such as social, political, cultural and economical dimension, and it indi- 
Table 1. Absolute and Relative Frequencies of Perceived Stress Categories

\begin{tabular}{lrr}
\hline Intensity of Perceived Stress & Number & Percentage \\
\hline Low $(\mathbf{1 4}-\mathbf{3 2})$ & - \\
\hline Moderate $(\mathbf{3 3}-\mathbf{5 1})$ & 1080 & - \\
\hline Severe $(\mathbf{5 2}-\mathbf{7 0})$ & 1320 & 45 \\
\hline Total & 2400 & 55 \\
\hline Standard deviation \pm mean & 100 \\
\hline
\end{tabular}

cates the role of stress in development of cardiovascular diseases.

According to the American heart association (10) ageing is accompanied with an increase of cardiovascular diseases. The findings of the research according to the age factor were compatible with the results of Framingham's research. Framingham's research showed that $45 \%$ of subjects had more than 65 years of age, and only $5 \%$ had less than 40 years of age $(36,37)$. Therefore, it is believed that the age factor is responsible for arteriosclerosis. The results of this research indicated that the rate of males affected by cardiovascular diseases was more than females. The results of previous researches also showed that the prevalence of cardiovascular diseases in males was more than females. The reason for this matter may be due to hormonal differences between males and females. The results of Framingham's research in 1976 indicated that the incidence of cardiovascular diseases in females after menopause was 2.6 times more than females before menopause. The risk of cardiovascular diseases in females that had reached menopause by surgery was 2.7 times more than females at the same age that had not reached menopause. Also, this risk was 2.2 times more that females that had reached menopause normally (38-42).

Regarding education, most of the subjects were illiterate. This indicates the necessity and importance of education especially to learn about preventing cardiovascular diseases and emphasizes the role and importance of education to develop people's ability to deal correctly with difficulties and life problems and find right resolutions to encounter life stressors and to control them.

Sixty-five percent of the subjects did not have high blood pressure and only $35 \%$ of them had high blood pressure (systolic blood pressure more than $140 \mathrm{~mm} / \mathrm{hg}$ and diastolic more than $90 \mathrm{~mm} / \mathrm{hg}$ ), while $94 \%$ did not have blood pressure in the past. The results of researches also indicate that high systolic and diastolic blood pressures are accompanied by other risk factors and also are the most important factors for the development of cardiovascular diseases (41).

The results of this research revealed that the mean stress intensity in patients with high blood pressure was significantly higher than people without high blood pressure. Regarding the activation of biological stress responses, release of neurotransmitters of the sympathetic system such as epinephrine. So, it makes the rate of blood pressure higher in persons with high stress $(26,43)$.

According to the association with diabetes, the results of the research indicated that $84.5 \%$ of the subjects were not affected by diabetes but $15.5 \%$ were affected by diabetes. Also the results of this research showed that the mean stress intensity in the subjects without diabetes was higher than the subjects with diabetes although this difference was not significant. The results of this research indicated that $34 \%$ of the subjects were either current smokers or had a history of smoking cigarettes and $66 \%$ of them had not smoked cigarettes at all. The results of the research indicated that the mean perceived stress in cigarette smoking subjects was less than the other two groups (nonsmokers and patients that had given up smoking). This may be because of the belief that cigarette smoking will relief and decline stress.

The results indicated that subjects, who performed regular exercise, had less stress than the subjects that did not. Therefore, exercise through increasing a person's psychological comfort and releasing their energy can decrease stress (44).

Regarding employment, the highest rate of stress was seen in unemployed subjects. Also the rate of perceived stress had significant differences between various jobs. This may be because of the various stressors of different jobs $(5,45)$.

The results of this research revealed that there were significant differences between the mean of perceived stress in subjects with high serum cholesterol and triglyceride levels compared with subjects with normal serum cholesterol and triglyceride levels. This may be because of the utilization of fat decreasing medications by the subjects.

\subsection{Conclusion}

The findings of this research indicated that the rate of stress between the affected patients with myocardial in- 
Table 2. Comparing Gender, Education Level, Hypertension, History of Hypertension, Diabetes, Cigarette Smoking, Doing Exercise, Job, and Family History of Myocardial Infarction With Perceived Stress Categories

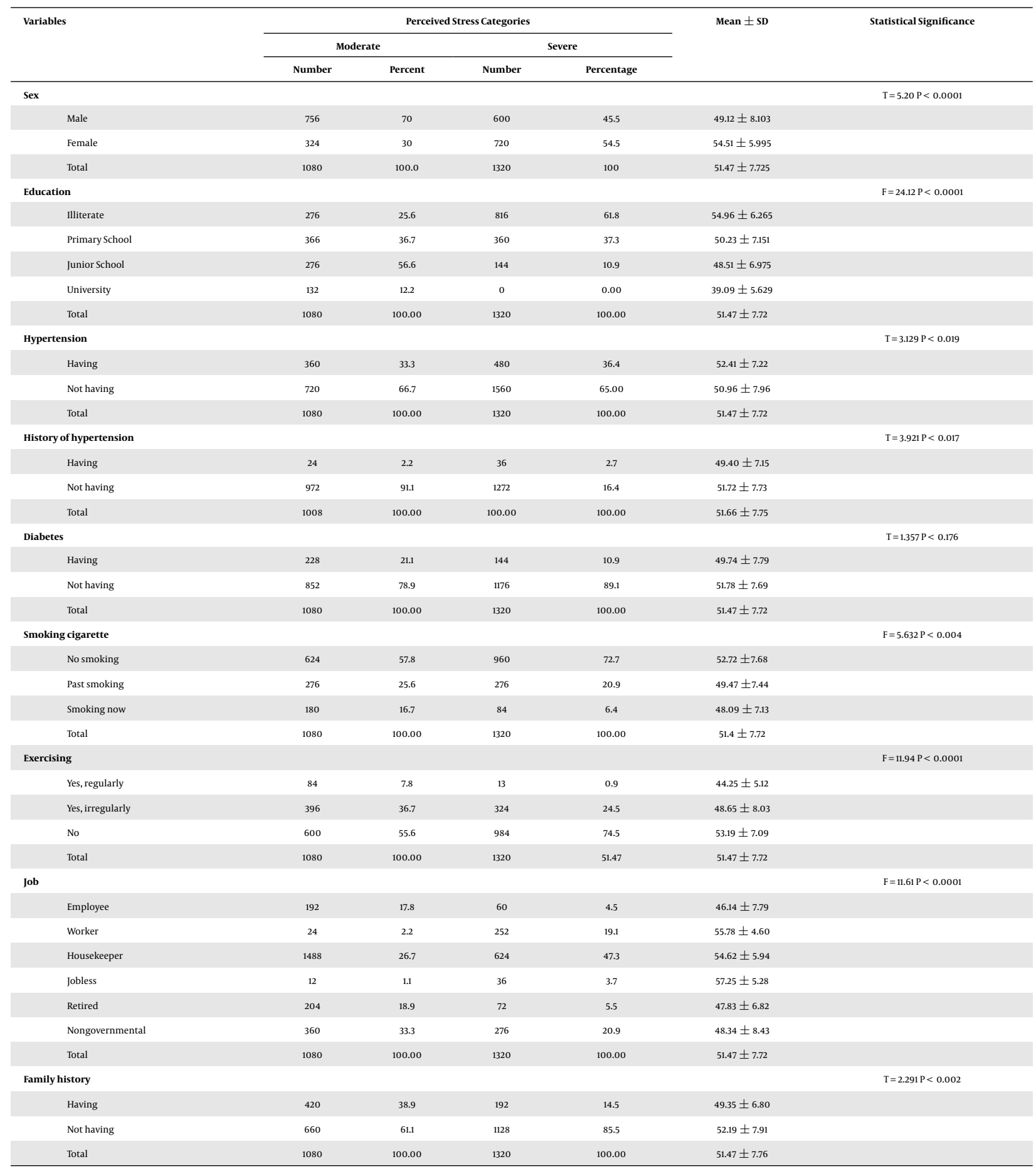


farction is moderate to high; thus, it is a very strong risk factor for the onset and acceleration of cardiovascular diseases. Therefore, it is necessary to take stress into consideration and decrease it, by designing educational programs to determine its preterm resources. Increasing awareness and education especially for the patients, affected by cardiovascular diseases in the whole society is of great importance.

\section{Acknowledgments}

The researchers thank all patients that sincerely helped us complete this research; moreover, special thanks goes to clinical research development center of Loghman Hakim hospital and Shahid Beheshti University of Medical Sciences for their methodological support.

\section{References}

1. Ghods R, Gharooni M, Amin G, Nazem E, Nikbakht Nasrabadi A. Hypertension from the perspective of Iranian traditional medicine. Iran Red Crescent Med J. 2014;16(3):16449. doi: 10.5812/ircmj.16449. [PubMed: 24829789].

2. Avazeh A, Hajiesmaeili MR, Vahedian-Azimi A, Naderi A, Madani J. Effect of progressive muscle relaxation on patients lifestyle with myocardial infarction: A double-blinded randomized controlled clinical trial. Knowledge Health. 2015;10(3):1-8.

3. Avazeh A, Jahanpour F, Mehrpoor G, Hajiesmaeili MR, Vahedian-azimi A, Naderi A. Effect of progressive muscle relaxation technique on the self-esteem of myocardial infarction patients: A randomized controlled clinical trial study. Nurs J Vulnerable. 2015;2(3):69-78.

4. Vahedian Azimi A, Alhani F, Ahmadi F, Kazemnejad A. Effect of familycentered empowerment model on the life style of myocardial infarction patients. J Critical Care Nurs. 2010;2(4):1-2.

5. Vahedian Azimi A, Sadeghi M, Movafegh A, Sorouri Zanjani R, Hasani $\mathrm{D}$, Salehmoghaddam AR, et al. The relationship between perceived stress and the top five heart disease characteristics in patients with myocardial infarction. ZUMS. 2012;78(3):99-111.

6. Vahedian Azimi A, Payami Bousari M, Kashshafi MB. The effect of progressive muscle relaxation on perceived stress of patients with myocardial infarction. ZUMS. 2012;20(81):18-27.

7. De Luca L, Olivari Z, Farina A, Gonzini L, Lucci D, Di Chiara A, et al. Temporal trends in the epidemiology, management, and outcome of patients with cardiogenic shock complicating acute coronary syndromes. Eur J Heart Fail. 2015;17(11):1124-32. doi: 10.1002/ejhf.339. [PubMed: 26339723].

8. Cosker K, Samson S, Fagot-Campagna A, Woimant F, Tuppin P. First hospitalization for transient ischemic attack in France: Characteristics, treatments and 3-year outcomes. Rev Neurol (Paris). 2016;172(2):152-9. doi: 10.1016/j.neurol.2015.06.008. [PubMed: 26318894].

9. Augustin AC, de Quadros AS, Sarmento-Leite RE. Early sheath removal and ambulation in patients submitted to percutaneous coronary intervention: a randomised clinical trial. Int J Nurs Stud. 2010;47(8):93945. doi: 10.1016/j.ijnurstu.2010.01.004. [PubMed: 20176355].

10. Mozaffarian D, Benjamin EJ, Go AS, Arnett DK, Blaha MJ, Cushman M, et al. Heart disease and stroke statistics-2015 update: a report from the American Heart Association. Circulation. 2015;131(4):29-322. doi: 10.1161/CIR.0000000000000152. [PubMed: 25520374].

11. Theroux P. Perspectives on acute coronary syndromes. Can J Cardiol. 2005;21(12):1053-60. [PubMed: 16234889].
12. Mozaffarian D, Benjamin EJ, Go AS, Arnett DK, Blaha MJ, Cushman M, et al. Executive Summary: Heart Disease and Stroke Statistics-2016 Update: A Report From the American Heart Association. Circulation. 2016;133(4):447-54. doi: 10.1161/CIR.0000000000000366. [PubMed: 26811276].

13. Mozaffarian D, Benjamin EJ, Go AS, Arnett DK, Blaha MJ, Cushman M, et al. Heart Disease and Stroke Statistics-2016 Update: A Report From the American Heart Association. Circulation. 2016;133(4):38-360. doi: 10.1161/CIR.0000000000000350. [PubMed: 26673558].

14. Vahedian-Azimi A, Miller AC, Hajiesmaieli M, Kangasniemi M, Alhani F, Jelvehmoghaddam $\mathrm{H}$, et al. Cardiac rehabilitation using the FamilyCentered Empowerment Model versus home-based cardiac rehabilitation in patients with myocardial infarction: a randomised controlled trial. Open Heart. 2016;3(1):000349. doi: 10.1136/openhrt-2015000349. [PubMed: 27110376].

15. Duan SY, Xing CY, Zhang B, Chen Y. Detection and evaluation of renal biomarkers in a swine model of acute myocardial infarction and reperfusion. Int J Clin Exp Pathol. 2015;8(7):8336-47. [PubMed: 26339403].

16. Brindle P, Emberson J, Lampe F, Walker M, Whincup P, Fahey T, et al. Predictive accuracy of the Framingham coronary risk score in British men: prospective cohort study. BMJ. 2003;327(7426):1267. doi: 10.1136/bmj.327.7426.1267. [PubMed: 14644971].

17. Vahedian-Azimi A, Hajiesmaeili M, Amirsavadkouhi A, Jamaati H, Izadi M, Madani SJ, et al. Effect of the Cardio First Angel device on CPR indices: a randomized controlled clinical trial. Crit Care. 2016;20(1):147. doi: 10.1186/s13054-016-1296-3. [PubMed: 27184664].

18. Nanchahal K, Duncan JR, Durrington PN, Jackson RT. Analysis of predicted coronary heart disease risk in England based on Framingham study risk appraisal models published in 1991 and 2000. BMJ. 2002;325(7357):194-5. [PubMed: 12142307].

19. Mamudu HM, Paul T, Veeranki SP, Wang L, Panchal HB, Budoff M. Subclinical Atherosclerosis and Relationship With Risk Factors of Coronary Artery Disease in a Rural Population. Am J Med Sci. 2015;350(4):257-62. doi: 10.1097/MAJ.0000000000000548. [PubMed: 26332729].

20. de la Camara AG, Guerravales JM, Tapia PM, Esteban EA, del Pozo SV, Sandubete EC, et al. Role of biological and non biological factors in congestive heart failure mortality: PREDICE-SCORE: a clinical prediction rule. Cardiol J. 2012;19(6):578-85. [PubMed: 23224919].

21. Gaby AR. Nutritional treatments for acute myocardial infarction. Altern Med Rev. 2010;15(2):113-23. [PubMed: 20806996].

22. Marano G, Harnic D, Lotrionte M, Biondi-Zoccai G, Abbate A, Romagnoli E, et al. Depression and the cardiovascular system: increasing evidence of a link and therapeutic implications. Expert Rev Cardiovasc Ther. 2009;7(9):1123-47. doi: 10.1586/erc.09.78. [PubMed: 19764865].

23. Blumenthal JA. Depression and coronary heart disease: association and implications for treatment. Cleve Clin J Med. 2008;75 Suppl 2:S48 53. [PubMed: 18540147$]$.

24. Rugulies R. Depression as a predictor for coronary heart disease. a review and meta-analysis. Am J Prev Med. 2002;23(1):51-61. [PubMed: 12093424].

25. Woods SL, Froelicher ESS, Motzer SA, Bridges EJ. Cardiac nursing. Lippincott Williams and Wilkins; 2005.

26. Urden LD. It's time to be strategic. J Nurs Adm. 2006;36(6):285-7. [PubMed: 16766905].

27. Lu Q, Zeltzer LK, Tsao JC, Kim SC, Turk N, Naliboff BD. Heart rate mediation of sex differences in pain tolerance in children. Pain. 2005;118(12):185-93. doi: 10.1016/j.pain.2005.08.008. [PubMed:16213093].

28. Drummond PD. The effect of pain on changes in heart rate during the Valsalva manoeuvre. Clin Auton Res. 2003;13(5):316-20. doi: 10.1007/s10286-003-0127-1. [PubMed: 14564653].

29. Girio-Fragkoulakis C, Gardner C, Cross S, Mason S, Walters S. Assessing the impact older people from care homes place on 
the emergency services. Eur J Emerg Med. 2011;18(2):81-5. doi: 10.1097/MEJ.ob013e32833e07f8. [PubMed: 20729739].

30. Sacco M, Meschi M, Regolisti G, Detrenis S, Bianchi L, Bertorelli M, et al. The relationship between blood pressure and pain. J Clin Hypertens (Greenwich). 2013;15(8):600-5. doi: 10.1111/jch.12145. [PubMed: 23889724].

31. Bruehl S, Chung OY, Ward P, Johnson B, McCubbin JA. The relationship between resting blood pressure and acute pain sensitivity in healthy normotensives and chronic back pain sufferers: the effects of opioid blockade. Pain. 2002;100(1-2):191-201. [PubMed: 12435472].

32. al'Absi M, Petersen KL. Blood pressure but not cortisol mediates stress effects on subsequent pain perception in healthy men and women. Pain. 2003;106(3):285-95. [PubMed: 14659511].

33. Manias E, Gibson SJ, Finch S. Testing an educational nursing intervention for pain assessment and management in older people. Pain Med. 2011;12(8):1199-215. doi: 10.1111/j.1526-4637.2011.01181.x. [PubMed: 21714844].

34. Gonzalez-Ramirez MT, Rodriguez-Ayan MN, Hernandez RL. The perceived stress scale (PSS): normative data and factor structure for a large-scale sample in Mexico. Span J Psychol. 2013;16:47. doi: 10.1017/sjp.2013.35. [PubMed: 23866243].

35. Ingram P, Clarke E, Lichtenberg JW. Confirmatory Factor Analysis of the Perceived Stress Scale-4 in a Community Sample. Stress Health. 2016;32(2):173-6. doi: 10.1002/smi.2592. [PubMed: 24995556].

36. Bian Y, Xu F, Lv RJ, Wang JL, Cao LJ, Xue L, et al. An early warning scoring system for the prevention of acute heart failure. Int J Cardiol. 2015;183:111-6. doi: 10.1016/j.ijcard.2015.01.076. [PubMed: 25662073].

37. Bastuji-Garin S, Deverly A, Moyse D, Castaigne A, Mancia G, de Leeuw $\mathrm{PW}$, et al. The Framingham prediction rule is not valid in a European population of treated hypertensive patients. J Hypertens.
2002;20(10):1973-80. [PubMed: 12359975].

38. Jukic AM, Weinberg CR, Wilcox AJ, McConnaughey DR, Hornsby P, Baird DD. Accuracy of reporting of menstrual cycle length. Am J Epidemiol. 2008;167(1):25-33. doi: 10.1093/aje/kwm265. [PubMed: 17928401].

39. Collins P, Rosano G, Casey C, Daly C, Gambacciani M, Hadji P, et al. Management of cardiovascular risk in the peri-menopausal woman: a consensus statement of European cardiologists and gynaecologists. EurHeartJ. 2007;28(16):2028-40. doi:10.1093/eurheartj/ehm296. [PubMed: 17644507].

40. Paoletti R, Wenger NK. Review of the International Position Paper on Women's Health and Menopause: a comprehensive approach. Circulation. 2003;107(9):1336-9. [PubMed: 12628957].

41. Hulley S, Furberg C, Barrett-Connor E, Cauley J, Grady D, Haskell W, et al. Noncardiovascular disease outcomes during 6.8 years of hormone therapy: Heart and Estrogen/progestin Replacement Study follow-up (HERS II).JAMA. 2002;288(1):58-66. [PubMed: 12090863].

42. Grady D, Herrington D, Bittner V, Blumenthal R, Davidson M, Hlatky $\mathrm{M}$, et al. Cardiovascular disease outcomes during 6.8 years of hormone therapy: Heart and Estrogen/progestin Replacement Study follow-up (HERS II).JAMA. 2002;288(1):49-57. [PubMed: 12090862].

43. Zarrindast MR, Nasehi M, Hoseinpourfard M. A Mini Review of Serotonin and Its Receptors. Int J Med Rev. 2014;1(1):39-45.

44. Bakalis N. Clinical decision-making in cardiac nursing: a review of the literature. Nurs Stand. 2006;21(12):39-46. doi: 10.7748/ns2006.11.21.12.39.c6386. [PubMed: 17195383].

45. Coomber B, Barriball KL. Impact of job satisfaction components on intent to leave and turnover for hospital-based nurses: a review of the research literature. Int J Nurs Stud. 2007;44(2):297-314. doi: 10.1016/j.ijnurstu.2006.02.004. [PubMed:16631760] 